\title{
Permeability of commercial landscapes: integrating plantation forest trackways into ecological networks
}

\author{
Paul Wolstenholme $\cdot$ Scott M. Pedley $\mathbb{D}$
}

Received: 19 July 2019 / Accepted: 1 March 2021 / Published online: 17 March 2021

(C) The Author(s) 2021

\begin{abstract}
Context Reconnecting fragmented habitat is a major challenge in biodiversity conservation. It is especially important in landscapes that have undergone significant change through agriculture and forestry conversion. This is particularly prevalent within heathland regions across Western Europe where remaining fragments are significantly isolated in intensely managed landscapes.

Objectives This study examines to what extent forest trackways can facilitate connectivity between open patches, and how invertebrate dispersal ability (terrestrial or aerial) influences functional landscape connectivity. We also investigate a range of management scenarios to examine the efficacy of landscape management plans to facilitate connectivity for vulnerable invertebrate communities.

Methods We develop the Path-Cost Index (PCI) that combines multiple environmental factors to quantify species-specific habitat suitability within forestry trackways. The PCI generates dispersal cost values for resistance-based connectivity models that represent specific forest environments and species/
\end{abstract}

Supplementary Information The online version contains supplementary material available at https://doi. org/10.1007/s10980-021-01229-3.

P. Wolstenholme $\cdot$ S. M. Pedley $(\bowtie)$

Department of Natural Sciences, Manchester Metropolitan

University, Chester Street, Manchester M1 5GD, UK

e-mail: s.pedley@mmu.ac.uk guild responses. We demonstrate the use of this index through the modelling of least-cost pathways for heathland invertebrates and test management scenarios (clustered and contiguous habitat improvements) developed to support heathland biodiversity.

Results The plantation landscape provided significant barriers for vulnerable heathland invertebrate guilds. Landscape metrics indicate that management plans incorporating contiguous corridors would provide significantly greater improvements over clustered corridors for target invertebrate guilds in our study landscape.

Conclusion The PCI presented in this study delivered easily definable resistance costs allowing comparative assessment of landscape enhancements plans. The $P C I$ can be easily adapted to other linear features and landscapes, affording a low-cost tool to assist the evaluation of management plans and biological networks.

Keywords Connectivity - Landscape management . Least-cost pathways · Heathland - Invertebrates · Corridor

\section{Introduction}

Fragmentation and isolation of natural systems are among the key issues facing biodiversity (Millennium Ecosystem Assessment 2005; Wilson et al. 2016). Loss of connectivity increases the risk of localised 
extinction due to stochastic events and inbreeding depressions, and limits species ability to disperse for seasonal migrations, recolonisation and range shifts (Fahrig 2003; Haddad et al. 2015). These issues are becoming increasingly important as species attempt to adapt to changing climates in increasingly fragmented landscapes (Mantyka-Pringle et al. 2012). In order to facilitate species movement, conservation efforts to restore connectivity are strongly encouraged (Lawton et al. 2010), as are actions that attempt to influence microclimates within existing habitats (Greenwood et al. 2016). Across commercially productive landscapes, such as those incorporating intensive agriculture and/or silviculture, opportunities to promote connectivity between natural or semi-natural habitats may be rare. However, it is often these habitats that provide the most significant barriers to dispersal and therefore require solutions to facilitate landscape permeability.

Global perceptions of fragmentation often focus on the impact of deforestation within native forests, but with high levels of habitat conversion and little protection, temperate grasslands, savannas and shrublands may be most at risk (Hoekstra et al. 2005). This is particularly prevalent in Western Europe, where semi-natural heathland habitats have experienced declines of up to $94 \%$ due to agricultural conversion and commercial afforestation (Gimingham 1992; Farrell 1993). This loss has left remaining habitat degraded, fragmented and isolated (Telfer and Eversham 1996; Piessens et al. 2005). With many rare and internationally important species still present within remnant heathland patches (Piessens and Hermy 2006; Dolman et al. 2012), the restoration and conservation of these habitats are a priority. Typically, conservation efforts for these habitats require low intensity grazing and episodic cultivation to encourage the re-establishment of characteristic early succession, shade-intolerant plant communities and associated microclimates (Dolman and Sutherland 1992; Pedley et al. 2013b).

The effectiveness of habitat restoration may be limited if habitat patches remain isolated within a heterogeneous matrix (Taylor et al. 1993; Isaac et al. 2018). In systematized plantation and agricultural settings, there is potential for connectivity to be facilitated by linear strips of habitat in the form of trackways (including access routes and fire breaks), hedgerows, unplanted headlands, and riparian vegetation. In the forestry context, access trackways have often been found to support populations of grass and heathland species (Eycott et al. 2006; Bertoncelj and Dolman 2013a; Pedley et al. 2013a), whereas hedgerows have been shown to facilitate the movement of forest dependent species (Wehling and Diekmann 2009; Dondina et al. 2016). However, the effectiveness of these linear features as dispersal-routes will be dependent on the microclimatic conditions within them, and how these are perceived by individual species (Greatorex-Davies et al. 1994; Sparks et al. 1996). This represents a significant challenge when attempting to assess the connectivity of open habitat networks as mosaics of planted tree stands that vary in age, height and size, influence conditions within trackway networks resulting in significant variation in shade and moisture (Warren 1985; Pedley et al. 2013a; Bertoncelj and Dolman 2013b).

In this study, we present a quantitative solution for assessing habitat suitability in the form of a simple index (Path-Cost Index) which generates landscape and species specific 'cost' values for linear features. Parameters for the index can be derived from readily available landscape data (e.g., national hedgerow inventories or plantation forest databases) to allow a rapid, economical solution for scoring the microclimates of linear features, which are then included in landscape analysis. We demonstrate the functionality of the index through its use in Geographic Information System (GIS) weighted approaches within resistance models, applying the generated Path-Cost Index values to landscape grids as representations of how each grid-cell either facilitates or restricts dispersal (Adriaensen et al. 2003). Using Thetford Forest, the largest lowland plantation forest in the UK as a case study, we apply the index through a graph-theoretic approach (Bunn et al. 2000; Urban et al. 2009) to determine least-cost pathways (LCP) between open habitats. Focusing on specialist heathland invertebrates, we further apply a dispersal guild approach, separating species into meaningful groups based on their dispersal ability and applying a cost threshold in order to determine existing ecological networks for each guild (Lechner et al. 2017).

The connections identified through LCP analysis are then used to address the following questions: (i) To what extent can forest trackways facilitate connectivity between open patches? (ii) How does invertebrate dispersal ability influence the functional 
connectivity of the landscape? We further demonstrate the index's use in landscape planning by applying our model to test landscape management scenarios for open habitat within Thetford Forest. The results of which will determine the effectiveness of improving landscape connectivity for vulnerable heathland invertebrate communities.

\section{Methods and materials}

\section{The Path-Cost Index}

We developed the Path-Cost Index (PCI) as a quantitative solution for assessing habitat suitability of linear features with a strong weighting towards factors influencing shade. The $P C I$ generates landscape and species-specific resistance 'costs' for linear features. To be widely generalizable to other landscapes, we incorporate the following variables into the PCI: tree height $(H$, estimated height of a tree species based on its age), solar altitude $(a)$, solar azimuth $(\psi$, measured from $0^{\circ}$ north), track width ( $w$, where width is classified as the distance between the tree-lines on both adjacent sides of a forest track) and track orientation
( $B$, the bearing of each linear vertex, measured from $0^{\circ}$ north).

The PCI formula is adapted from a Gompertz function, which has been selected as a plausible function of xerophilic species perception to habitat suitability within varying shade conditions. In this case, an inverse of the function has been used to incorporate all the above variables (Eq. 1), where $P C I$ cost values follow a sigmoid curve pattern from a minimum cost value (determined by the model resolution $(r)$, set at the scale to which a species/guild is sensitive to environmental changes within the landscape, relative to the defined model distance measurement units), growing at an exponential rate with narrowing trackway widths $(w)$ before levelling off at a set cost threshold (rT) (Fig. 1):

$P C I=r\left((T-1) e^{-s e^{b w}}+1\right)$

As $e^{-s e^{b w}}$ has a range between 0 and 1 , the absolute maximum cost value is set by $r T$, where $T$ represents the relative cost expected to be incurred when dispersing through a single completely shaded trackway grid cell unit (i.e. if $r$ and $w$ are defined in meters then a single grid cell unit $(1 \mathrm{~m}$ resolution $)=1 \mathrm{~m} \times 1 \mathrm{~m})$, compared to that of an unshaded equivalent area.
Fig. 1 Plot depicting the rising cost of the $P C I$ with narrowing trackway widths at three different growth rates $(b)$, where for 1 : $b=0.25,2: b=0.5$, and 3 : $b=1$. Cost only increases after width decreases below the maximum shade extent $(E)$, and never rises above the relative cost threshold $(r T)$. Growth rate $(b)$ should reflect the tolerance of a species to shade

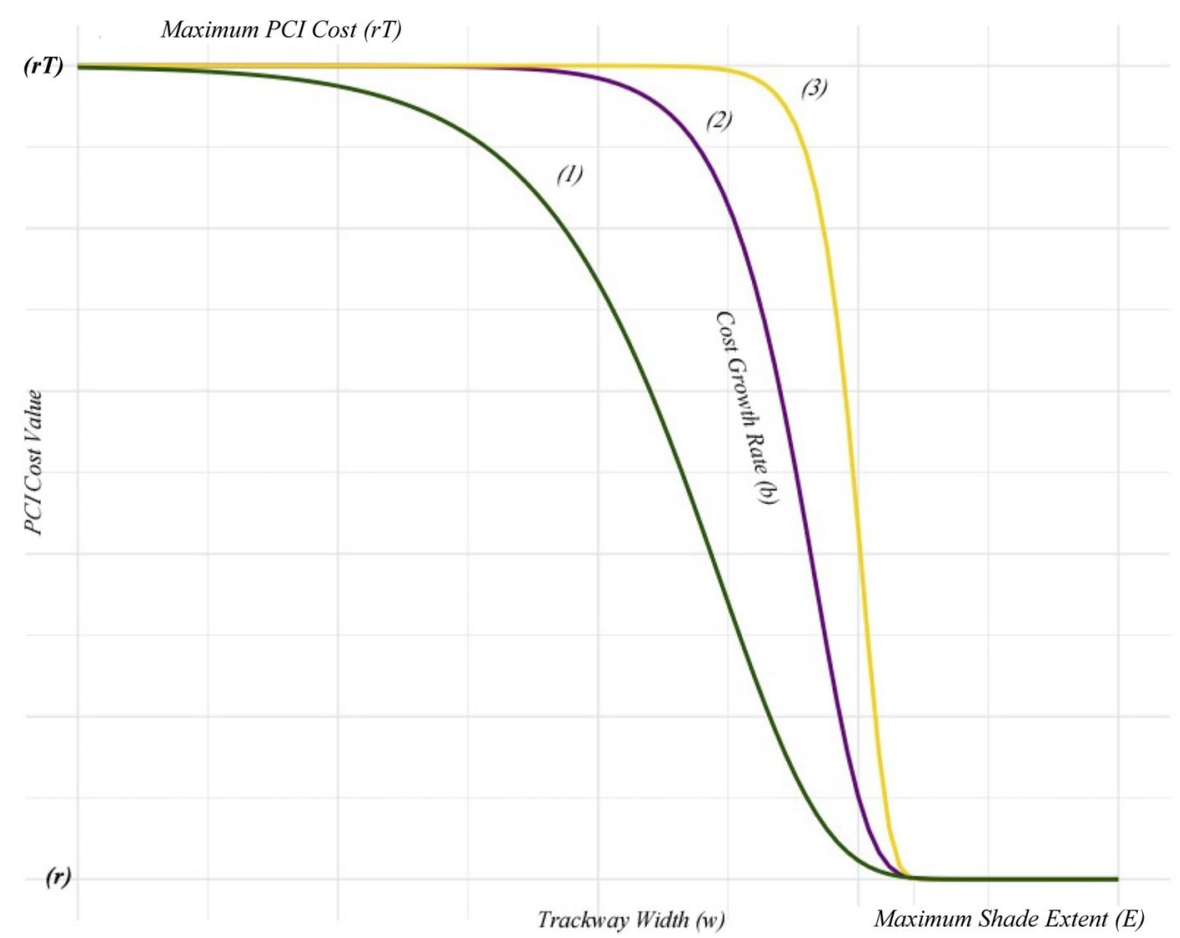


Varying shade conditions are incorporated into $P C I$ calculations through the determination of a cost initiation point (Fig. 1), set by the influence of the surrounding matrix factor ( $s$; calculated by Eq. 2, see below). This initiates cost growth at the point at which trackway widths $(w)$ decrease beyond the maximum shade extent ( $E$; calculated by Eq. 2, see below), where smaller values of $s$ are representative of increasing shade influence (i.e. when $s=0, P C I=r T$ ). The rate of cost growth is then determined by $b$, an arbitrary value that can be manipulated to set a rate relative to species tolerance to changing conditions of shade with changing trackway widths. Greater values of $b$ will set greater rates of relative cost growth for species with lower shade tolerances (Fig. 1). Quantitative examples of the influence of varying values of $b$ and $s$ are provided in Online Resource 1.

\section{The influence of the surrounding matrix (s)}

In order to establish open habitat conditions a trackway will be required to be significantly wide enough to counteract the maximum influence of shade, allowing a proportion of the ride to be continuously unshaded during the hours of peak solar energy (solar window) (Carter and Anderson 1987). The major determining factor of shade will be tree height, which will vary depending on tree species, age and climate (Ryan and Yoder 1997; Givnish et al. 2014). However, the extent of shade within the trackway is further determined by both the specific solar altitude and solar azimuth angle relative to the orientation of the trackway, for which values will vary significantly depending on the landscape location and specific time. In addition, depending on the defined solar window and relative orientation, shade may be exerted from the trees on both sides of the trackway. This will act to restrict continuously unshaded areas to the centre of the trackway, significantly reducing its suitability to establish open habitat conditions over those only shaded from one side. It is imperative that these factors are considered in cost calculations as they are the determinant influence on shade conditions and habitat suitability within trackways.

Within the PCI these factors are incorporated within the Influence of the Surrounding Matrix Factor $(s)$ which acts to set an initiation point for which 'cost' will begin to increase as trackway widths narrow (Fig. 1). For open habitat conditions, the initiation point would be required to be greater than the maximum shade extent $(E)$ over a defined solar window. Shade extent $(E)$ can be calculated by the following formula:

$E=(H \tan (a)) \sin (A)$

where $a$ is the solar altitude, $A$ is the relative bearing between the trackway and the solar azimuth $(\psi)$, and $H$ is the tree height (measured in the equivalent units of trackway width $(w)$ and model resolution $(r)$ ) which will be dependent on which side of the trackway shade is exerted. For cost calculations within the $P C I$, the maximum value of $E$ should be derived from within a set solar window. This can then be averaged over the defined activity period for the focal species or guild. Should shade be exerted from both sides of the trackway over this period, then $E$ should be equal to the sum of the maximum shade extent exerted on either side during the set window.

To manipulate the $P C I$ to incorporate $E$ into the cost calculation, we use the surrounding matrix factor $(s)$ (Eq. 3). This will set the cost initiation point as $E$, adjusting for different cost growth rates $(b)$ and maximum cost thresholds $(T)$ :

$s=-\left(\frac{\ln \left(\frac{0.1}{T}\right)}{e^{b E}}\right)$.

\section{Case study for Thetford Forest, UK}

\section{Study area}

Thetford Forest, Norfolk $\left(0^{\circ} 40^{\prime} \mathrm{E}, 52^{\circ} 27^{\prime} \mathrm{N}\right)$ is the UK's largest lowland forest, comprised of approximately 80\% Corsican (Pinus nigra) and Scots pine ( $P$. sylvestris). The forest is managed by rotational clear-felling and replanting of even aged stands (2-16 ha) that form a heterogeneous mosaic of growth stages. We focus specifically on the core forest area that represents $60.1 \%$ of the forest estate and occupies $112 \mathrm{~km}^{2}$ of the Breckland region within eastern England (Online Resource 2). A total of $7.66 \mathrm{~km}^{2}$ of this area is designated as permanently open habitat, in the form of isolated open-patch polygons and linear habitat strips comprising forest trackways and fire-breaks. These linear elements within the forest make up a significant 
amount of open space in the study area (trackway length $779 \mathrm{~km}$, average width $12.03 \mathrm{~m} \pm 5.94$, range 5-61 m). Additional open space is provided via ephemeral open patches formed within postfell, restocked stands (see Online Resource 3 for a map of landscape features in the study area) where open conditions persist for up to 7 years (Hemami et al. 2005; Lin et al. 2007; Pedley 2012). With the plantation forest of heathland origin and planted on largely nutrient-poor, sandy soils (Calcareous and Podzol, Online Resource 4), management of these areas (forage harvesting, grazing and other forms of vegetation removal) has encouraged characteristic heathland species, including many protected at national and European scales (Lin et al. 2007; Dolman et al. 2012; Pedley et al. 2013b). Consequently, designated open space within the forest is protected under UK conservation legislation (English Nature 2004) (Fig. 2).

\section{Heathland specialist invertebrates}

Our analysis focuses on the functional connectivity of specialist heathland invertebrates, defined as those restricted exclusively to grassland, heathland and sandy habitats. Within the forest, heathland invertebrates including nationally rare and scarce species have been recorded in permanent open areas, unshaded open trackways and young (1-7 years) restock stands (Lin et al. 2007; Pedley 2012; Pedley et al. 2013b). To incorporate the movements of multiple heathland species, we apply a dispersal guild approach by grouping species with similar dispersal ability and conducting analysis for each group following Lechner et al. (2017). To derive dispersal data, we conducted a literature search based on the heathland species recorded within the Breckland Biodiversity Audit (Dolman et al. 2012). Searches were conducted within Web of Science and Google Scholar, with a focus specifically on maximum lifetime dispersal distances. Online searches included the individual

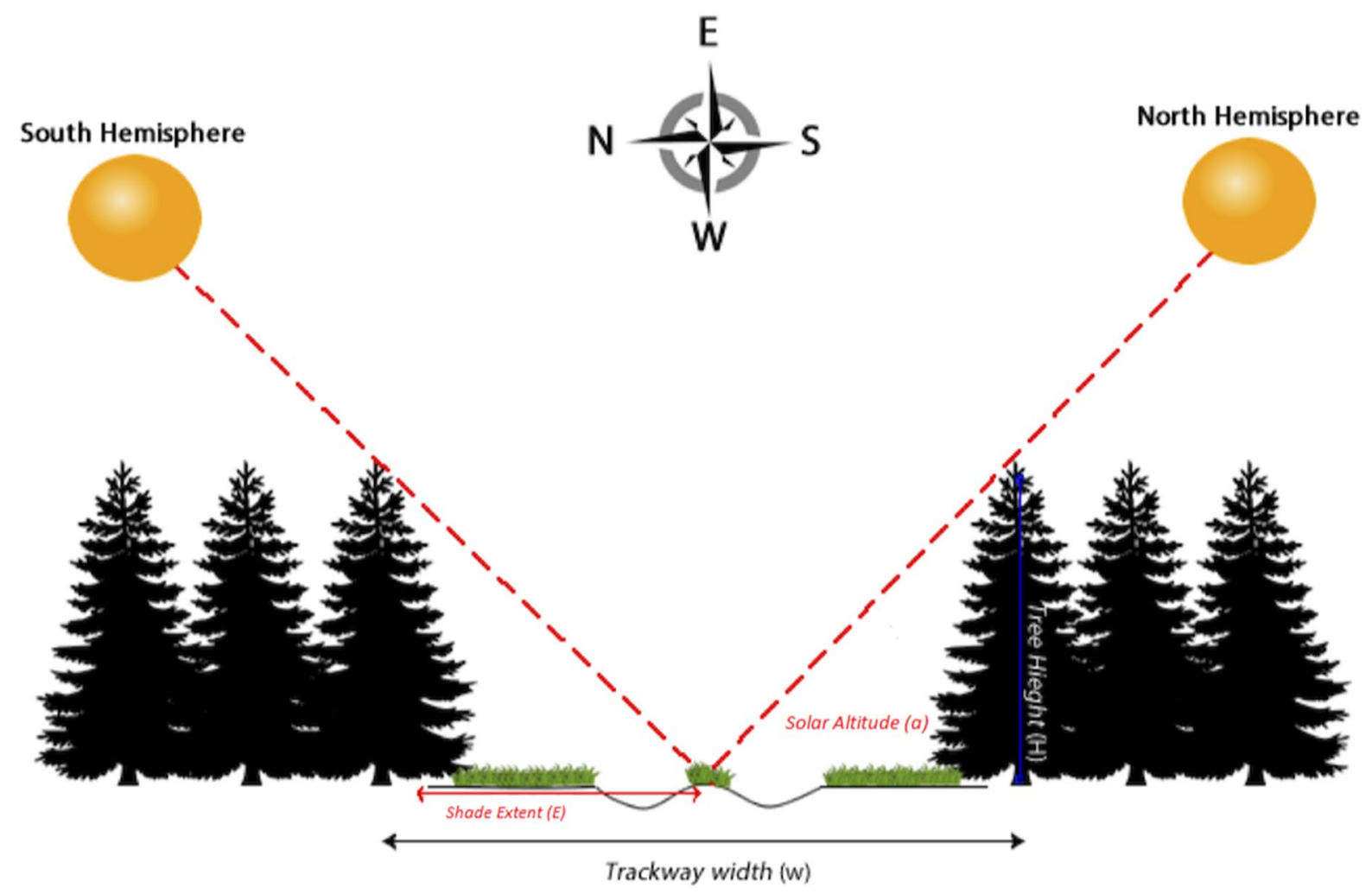

Fig. 2 Illustration depicting a typical forest trackway, demonstrating how tree height $(H)$ and solar altitude $(a)$ will influence east/ west orientated shade extent $(E)$ in both the northern and southern hemispheres 
species Latin name, including known synonyms, family name and the keywords: Dispersal, Ability, Maximum, Distance. The results of the literature search determined distances for $10 \%$ of the heathland species listed within the Breckland Biodiversity Audit (Online Resource 5). Significant differences were found between species that disperse aerially and those that rely mostly on ground-based movements $(\mathrm{t}=2.96, P<0.05)$. We therefore define two dispersal guilds, flight dispersive and ground dispersive, with mean maximum lifetime dispersal distances of $1208 \mathrm{~m}$ and $2897 \mathrm{~m}$ respectively. For LCP analysis, these distances are applied as dispersal cost threshold for each guild (Rayfield et al. 2016; Lechner et al. 2017).

\section{Landscape connectivity model}

The PCI formula is used to assign cost values to each element of the forest trackway. Formula parameters: stand age, soil type and trackway geolocation were derived from Forestry Commission maintained GIS data files (Forestry Commission 2017a), with trackway bearings calculated from the geographic coordinates of each linear trackway vertex. Trackway widths were measured using open source satellite imagery (Google Earth 2017) and validated with data collected by Pedley et al. (2013b). Forest stands were classified by separate age categories defined by Hemami et al. (2005), with each category assigned a mean stand height value based on the forest tree growth rates identified by Rowland et al. (2008) (Online Resource 6). Maximum shade extent for each trackway vertex was calculated over a solar window of 9 am-3 pm (considered to be peak solar hours within the UK), averaged over the period between April and October as the main activity period for regional invertebrates. Calculations were conducted within R-Statistical Software (R Development Core Team 2018) with solar altitude $(a)$ and azimuth $(\psi)$ derived from the R-package: microclima (Maclean et al. 2018). The full reproducible code is available in Online Resource 7.

Extensive invertebrate monitoring within Thetford Forest has demonstrated the responses of heathland invertebrates to the environmental conditions of various habitat types, including forest trackways of varying widths and surrounding forestry stands (Lin et al. 2007; Bertoncelj and Dolman 2013a; Pedley et al. 2013a, b). We incorporate this species-based information into the $P C I$ to set: an arbitrary cost growth rate $(b)$ of 0.2 , based on the variation found in assemblages between trackways of varying widths with similar adjacent stand heights; a maximum cost threshold $(T)$ of 50, based on the intolerance of heathland invertebrates to highly shaded environment; and a cell resolution $(r)$ of $1 \mathrm{~m}$, based on the high sensitivity of heathland invertebrates to changing environmental conditions.

Landscape elements not defined by the $P C I$ (e.g., forest stands and main roads) are assigned relative cost values based on their influence on invertebrate dispersal derived from previous studies (see Online Resource 6). These cost values and those calculated by the PCI, represent the cell resolution of the model (e.g., if resolution is $1 \mathrm{~m}$, a cell with no resistance would have a cost value of $1 \mathrm{~m}$ ) and the relative dispersal resistance for heathland invertebrates (e.g., if a $1 \mathrm{~m}$ cell has a $10 \times$ resistance it would have a relative cost value of $10 \mathrm{~m}$ ). Areas of any size within suitable environmental conditions are assumed to be able to support heathland vegetation (Piessens et al. 2005) and suitable habitat (source) patches are defined as areas with no dispersal resistance within heathland suitable soil types (calcareous brown earth and podzol, Online Resource 4). LCP's are then calculated between the most external vertex of each source using a graph-theoretic approach within Quantum GIS (QGIS Development Team 2009) using the LeastCost Path plugin (FlowMap Group@SESS-PKU 2020). In this approach, Dijkstra's breadth-first search algorithm is used to define the path of least resistance between each patch, and by setting a maximum cost threshold, potential connections between each habitat patch can be determined for each invertebrate dispersal guild.

\section{Conservation management}

Designated open space within Thetford forest (7\%) falls short of the minimum $10 \%$ required by forestry standards (UKWAS 2012; Forestry Commission 2017b). To address this the Forestry Commission propose to implement the Thetford Forest Open Habitat Plan (OHP), which aims to create an additional $7.51 \mathrm{~km}^{2}$ of open habitat through the widening of existing forest trackways to at least $40 \mathrm{~m}$, increasing open space within the estate to $11.13 \%$. The OHP 
design (Fig. 3c) is the result of historical priority species records, soil-types, archaeological influences and the impacts on timber income (Armour-Chelu et al. 2014; East of England Forestry Commission, Pers. Comm. 2018). Within our current study area the OHP equates to an addition of $4.9 \mathrm{~km}^{2}$ of open space, spread over $169 \mathrm{~km}$ of forest trackways. Using our connectivity model, we aim to test the effectiveness of the OHP for priority heathland invertebrates and compare the results against two alternative management strategies based on equal addition of open habitat area: (i) Strategy A aims to reduce the spatial isolation of open habitat within the forest by widening clusters of trackways in areas most devoid of open space (Fig. 3a), (ii) Strategy B aims to test the effectiveness of contiguous linear corridors created by widening existing forest trackways between open patches and external heathland (Fig. 3b). These two hypothetical strategies are not confined by the restrictions of timber income, underground services and archaeological features but are designed to provide comparative connectivity theories with which to assess the OHP. For each management strategy, suggested widening areas are incorporated into the landscape and dispersal cost are re-defined using the PCI. Strategy effectiveness is then compared by conducting least-cost path analysis between the newly defined source areas.

\section{Connectivity analysis: dispersal guilds}

For both invertebrate dispersal guilds (flight and ground dispersive), we compare the functional connectivity of the forestry landscape by determining the number of connected source patches and total connected source patch area within each network identified by the LCP models. Greater patch area and/or number of connected patches is indicative of more connected networks and can be interpreted as reducing open habitat isolation within the forest. We then further analyse the spatial aggregation of networks through the dispersion measures Euclidian Nearest

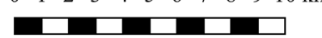

(a)

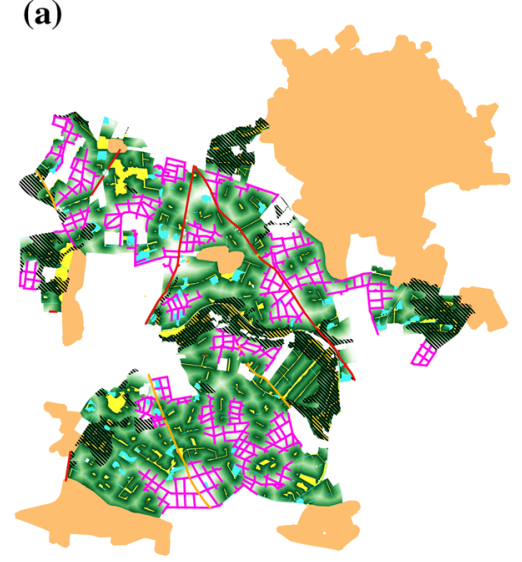

(b)

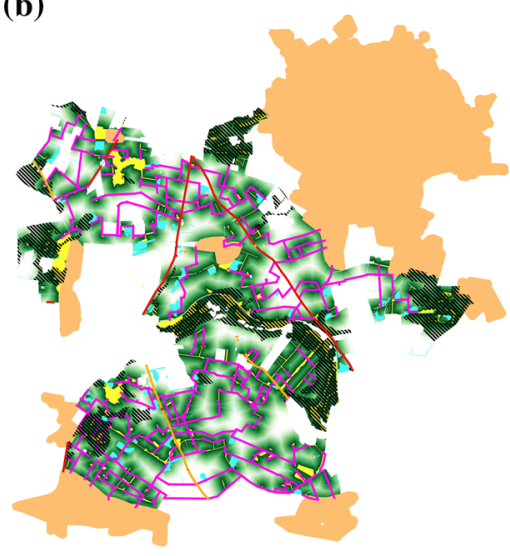

(c)

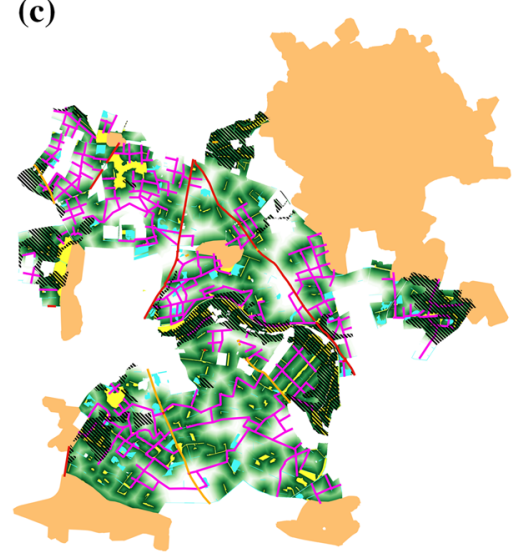

Fig. 3 Map showing suggested trackway widening areas for management Strategy A (a), Strategy B (b) and the Open Habitat Plan (c). Strategy A clusters management efforts within areas that are devoid of permanent open space, whereas Strategy B creates contiguous linear habitat that attempts to connect each permanent open patch within heathland suitable soils 
Neighbour (ENN) distance and the Proximity Index. ENN distance is a measure of network isolation that determines the shortest distance between one component and another, with larger values indicating greater isolation (McGarigal and Marks 1995). Whereas, the Proximity Index incorporates both patch area and distance, within a set search radius, with larger values representing larger and less isolated networks that is interpreted as a higher level of connectivity (Gustafson and Parker 1992). The search radius for each guild is set as their respective dispersal cost thresholds, providing ecological relevance to the index results. Dispersion measures were calculated in the open source software FRAGSTATS (McGarigal et al. 2012) and all measures were compared between ground and flight invertebrate guilds by non-parametric Mann-Whitney $\mathrm{U}$ tests conducted within R statistical software.

\section{Connectivity analysis: management strategy}

To examine how each management strategy influences open habitat connectivity, landscape metrics (network area, number of patches and Proximity index) are used to compare between the Original Forest Condition (OFC), the two theoretical management strategies, and the proposed Open Habitat Plan. For the number of source patches within each network, we focus on how management influences the connectivity of source patches identified within the forest in its current condition. For this, the additional management area is considered to act as connecting corridors and the number of original source patches connected within each network is used as a measure of open habitat connectivity. As the current source patches present are likely to act as areas of refugia for heathland invertebrates within the forest, a higher number of these patches connected within each network will help establish greater connectivity between populations, indicative of a more effective management strategy. The total area, including trackway widening through management, however, is used for source area per network and proximity index calculations to analyse how the overall open habitat network will be improved under each strategy. The ENN has been excluded from these comparisons as it was of negligible use for comparing between management Strategy as ENN distances are equally reduced. Comparisons of landscape metrics between management strategies were conducted using generalised linear models (GLMs) in R. The appropriate error term for each analysis was selected by comparing Akaike's Information Criterion (AIC) and examining patterns in residuals and model dispersion. Pairwise differences among management strategies were examined by Tukey post hoc tests using the glht function in the multcomp package (Hothorn et al. 2008). Chi-squared tests were used to examine differences in the total number of network components that were present after modelling each management strategy within the landscape.

\section{Results}

\section{Case study: current invertebrate connectivity}

In the study landscape, 413 isolated habitat source patches were identified, comprising a total area of $69.1 \mathrm{~km}^{2}$. These patches consist of permanent open areas, young replanted forest stands, external heathland and individual trackways with suitable habitat conditions (i.e. forestry trackways with a width greater than their calculated maximum shade extent, located within heathland suitable soils). From LCP analysis, we determined that the landscape is separated into 258 and 191 individual networks for ground dispersal and flight dispersal guilds respectively (Fig. 4). No significant difference in the average number of source patches within each network was found between the two dispersal guilds, and there was also no significant difference in the average source patch area per network between the dispersal guilds (Table 1). The networks calculated for the flight guild were found to be less isolated (greater proximity index) than those of the ground guild (Table 1). However, the mean Euclidean Nearest Neighbour (ENN) distance for the flight guild was higher than the ground guild, indicating larger distances between networks for the flight guild. Differences between these two metrics reflect the way in which they are calculated, with the proximity index also accounting for patch size (Table 1). Although the increased dispersal ability of the flight guild allows for fewer overall networks compared to the ground dispersal guild, a significant proportion of suitable patches remain isolated within the landscape for both dispersal guilds (Fig. 4). 


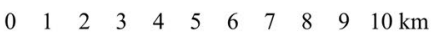

(a)

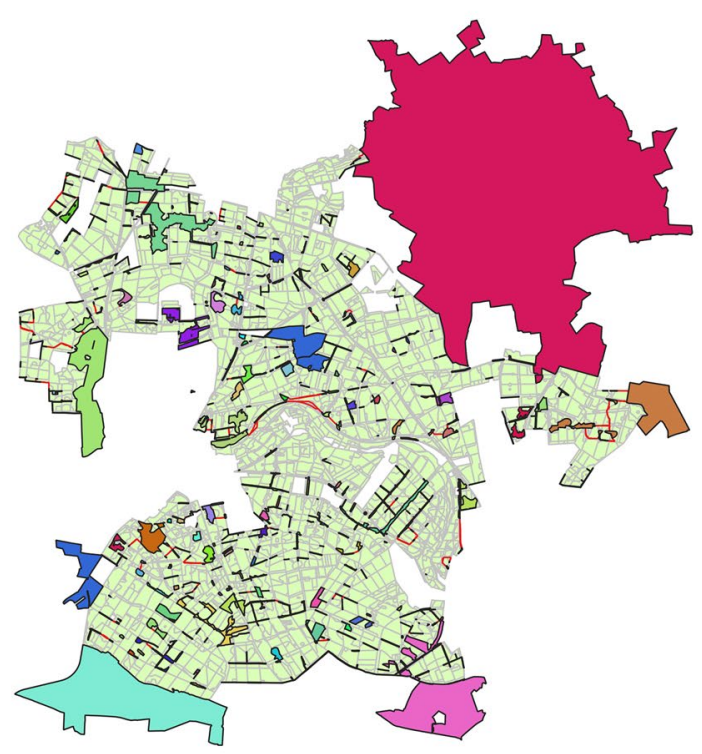

Forest Sub-Components

Least-Cost Pathways

Individual Network Habitat Patches

Fig. 4 Results of the least-cost path analysis for the Original Forest Condition. Maps show the individual connected source patch networks for the ground (a) and flight (b) dispersive (b)

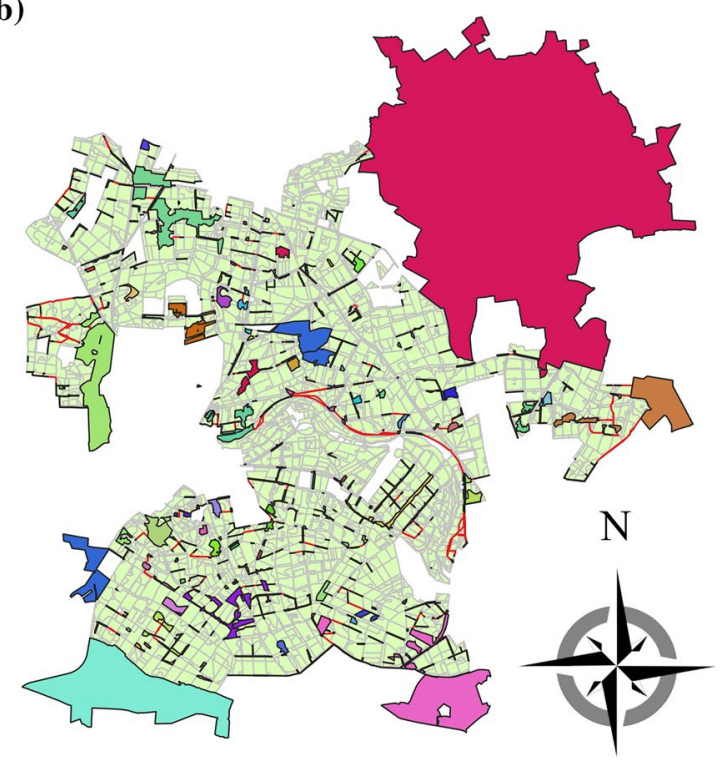

guilds. Areas highlighted by the same colour within the landscape are part of the same network with connecting least-cost pathways highlighted in red
Table 1 Mean, standard error and statistical results of non-parametric MannWhitney U tests between flight and ground dispersal guilds for each landscape metric

Values in bold refer to $p$-values $<0.05$

\begin{tabular}{llllr}
\hline Variable & $\begin{array}{l}\text { Ground } \\
(\text { mean } \pm S E)\end{array}$ & $\begin{array}{l}\text { Flight } \\
(\text { mean } \pm \text { SE) }\end{array}$ & $W$-value & $P$-value \\
\hline Source patches per network & $1.60 \pm 0.08$ & $2.16 \pm 0.19$ & 26,660 & 0.07 \\
Source area per network $\left(\mathrm{km}^{2}\right)$ & $0.27 \pm 0.18$ & $0.36 \pm 0.24$ & 26,394 & 0.20 \\
Euclidean Nearest Neighbour $(\mathrm{km})$ & $0.14 \pm 0.01$ & $0.17 \pm 0.01$ & 29,790 & $<\mathbf{0 . 0 0 1}$ \\
Proximity Index (logged) & $1.25 \pm 0.86$ & $1.42 \pm 0.67$ & 28,316 & $\mathbf{0 . 0 0 7}$ \\
\hline
\end{tabular}

\section{Case study: conservation management strategies}

The general response pattern of landscape metrics for the management strategies was similar across both dispersal guilds (Fig. 5, Online Resource 8). Patterns in network connectivity resulting from the LCP analyses of the management strategies can be seen in Fig. 6 for the ground dispersive guild, and Fig. 7 for the flight dispersive guild. Strategy B (contiguous linear corridors) had the greatest impact on improving connectivity with significantly greater proximity index values, hence greater landscape connectivity, compared with the other management strategies and the Original Forest Condition (Fig. 5). Strategy B also made significant improvements over the Original Forest Condition in the number of source patches per network, and also in the amount of source patch area per network. Although not significant $\left(\chi^{2}=2.62\right.$, $\mathrm{df}=3, \mathrm{P}>0.05)$, Strategy $\mathrm{B}$ also reduced the number of network components within the landscape, with suitable habitat split into 128 and 73 components for the ground and flight dispersal guilds respectively, 

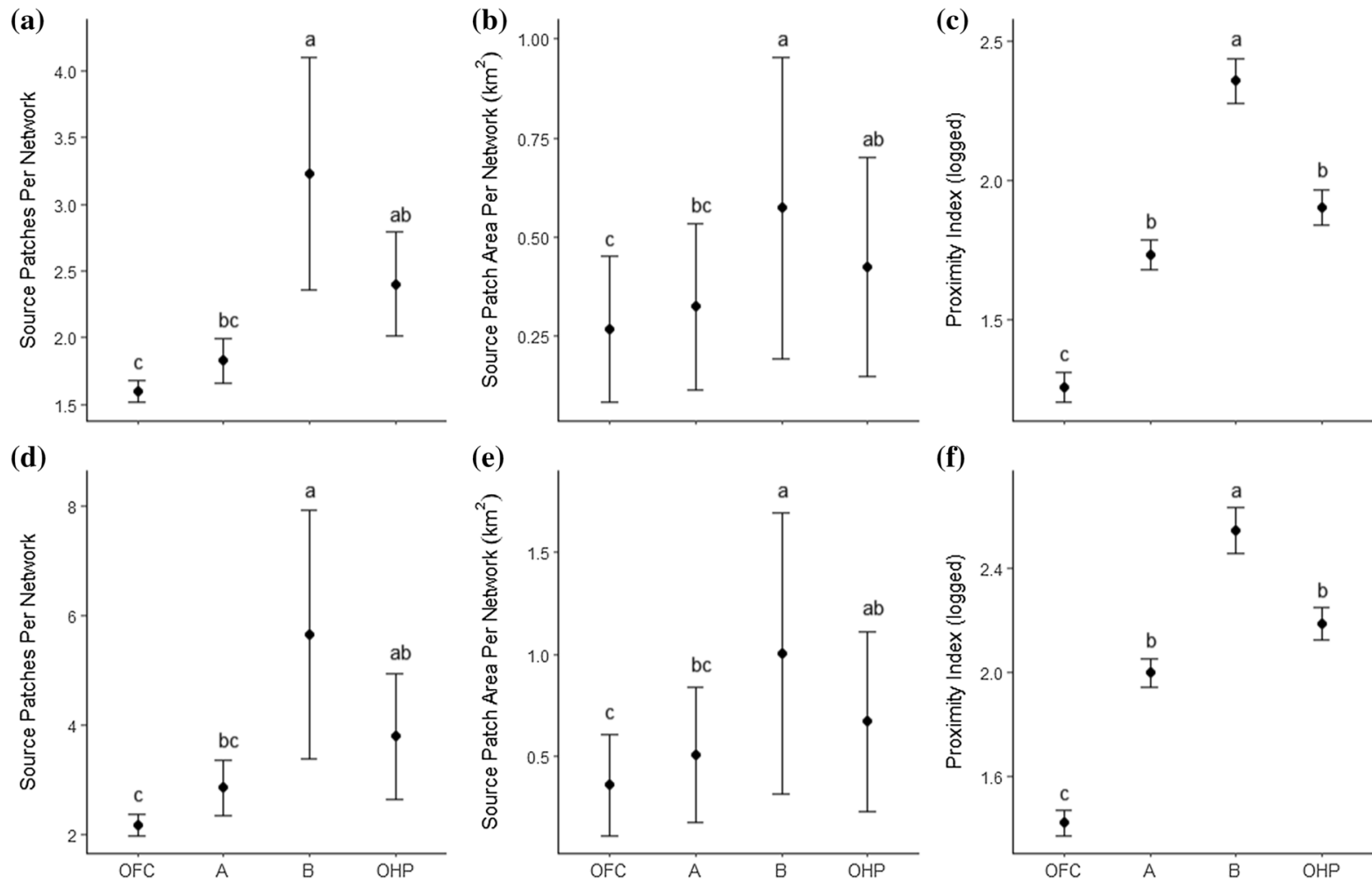

Fig. 5 Mean and standard error of the landscape connectivity metrics; source patches per network, source area per network $\left(\mathrm{km}^{2}\right)$ and Proximity Index for both ground $(\mathbf{a}-\mathbf{c})$ and flight (d-f) dispersive guilds, compared across each management strategy. Management strategies are Original Forest Condition

compared to 226 and 145 for Strategy A, and 172 and 109 for the Open Habitat Plan.

The Open Habitat Plan performed significantly better than the Original Forest Condition in all landscape metrics and this was consistent for both ground and flight dispersal guilds (Fig. 5). Mean metric calculations for the Open Habitat Plan were positioned between those of the contiguous (Strategy B) and clustered (Strategy A) management plans for all three metrics tested. Furthermore, the Open Habitat Plan was not significantly different to clustered management for the three metrics and was only significantly lower than the contiguous management plan for the proximity index (Fig. 5). Although the mean metric calculations for Strategy A were consistently greater than the Original Forest Conditions for all metrics, this clustered management strategy was only significantly greater than the Original Forest Condition for the proximity index (Fig. 5).
(OFC), Strategy A (A), Strategy B (B) and the Open Habitat Plan (OHP). GLMs followed by Tukey post hoc tests were used to identify homogeneous groups (ranked highest to lowest: a-c). Groups with the same letter do not differ significantly $(p>0.05)$. See Online Resource 8 for test statistics

There was a common trend across the three metrics that greater standard error appears to be associated with greater mean values (Fig. 5; Online Resource 8 ). It is likely this has arisen from the presence of many highly isolated source patches (Figs. 6, 7), and that despite management these patches will remain isolated in the landscape across all strategies. Therefore, as management activities increase the size of networks, the presence of persistent isolated patches within the landscape increases the variation in mean metric values.

\section{Discussion}

\section{Invertebrate connectivity}

Our analysis of connectivity for the Original Forest Condition found that although an extensive 
$\begin{array}{llllllllllll}0 & 1 & 2 & 3 & 4 & 5 & 6 & 7 & 8 & 9 & 10 & \mathrm{~km}\end{array}$

(a)

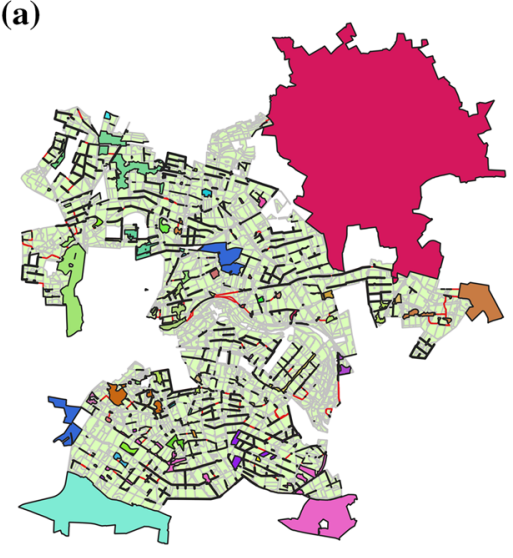

(b)

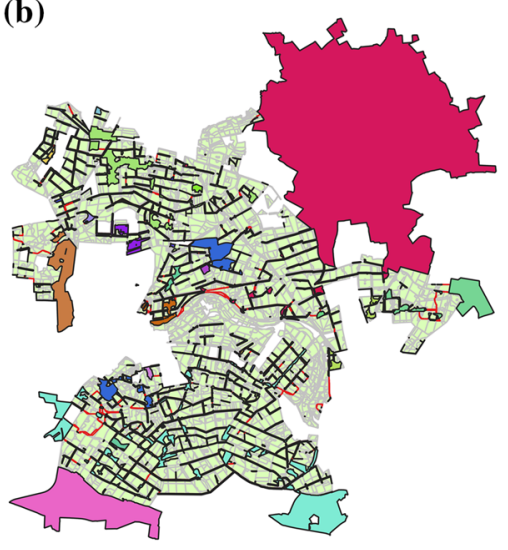

(c)

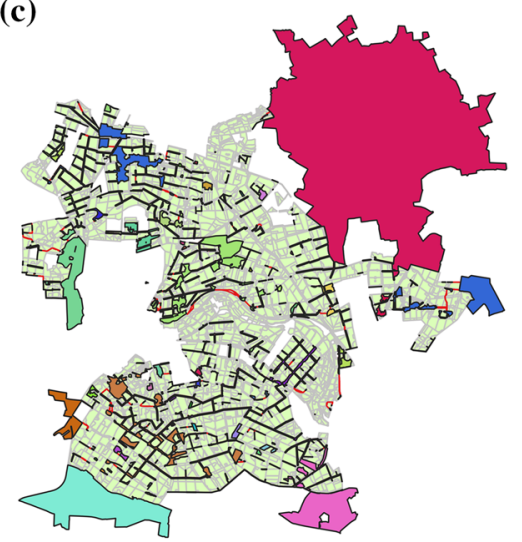

Forest Sub-Components

- Least-Cost Pathways
ㅍIIII Individual Network Habitat Patches

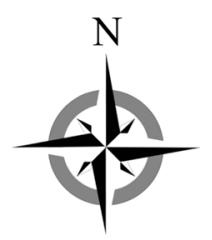

Fig. 6 Results of least-cost path analysis of the ground dispersive guild for management Strategy A (a), Strategy B (b) and the Open Habitat Plan (c). Patches of the same colour within

amount of suitable habitat exists within and surrounding Thetford Forest, connectivity between patches is limited. Unsurprisingly, landscape models for flight dispersive species were able to connect more patches than ground dispersers, but due to the spatial aggregation of open habitat in the forest this only equates to relatively small patches in close proximity of each other. A significant number of isolated patches remained in the forest for both dispersal guilds, demonstrating that for the Original Forest Condition the ability of forest trackways to facilitate dispersal may be limited, as even short lengths of unsuitable habitat within trackways present a significant barrier. For greater dispersal potential, heathland invertebrates require longer, connected lengths of low cost (e.g., low shade) trackways, which are rare in the Original Forest Condition due to the mosaic nature of the plantation landscape.

the landscape are part of the same network with connecting least-cost pathways highlighted in red

\section{Conservation management}

We found the most efficient management strategy for improving invertebrate connectivity, beyond the Original Forest Condition, is through the creation of contiguous linear strips of habitat linking existing open areas (Strategy B). By ensuring that these corridors are suitably wide, they not only provide lowcost dispersal routes, but also have the ability to support breeding populations (Bertoncelj and Dolman 2013a; Pedley et al. 2013a). This ensures that the effectiveness of these corridors are not restricted by their length, which is often a limitation in successful corridor creation for larger more dispersive taxa (Brodie et al. 2015). Supporting breeding populations within corridor habitat also facilitates the movement of the most dispersal restricted invertebrates, enabling them to disperse throughout the forest by multi-generational movements. Our results 
$\begin{array}{llllllllllll}0 & 1 & 2 & 3 & 4 & 5 & 6 & 7 & 8 & 9 & 10 & \mathrm{~km}\end{array}$

(a)

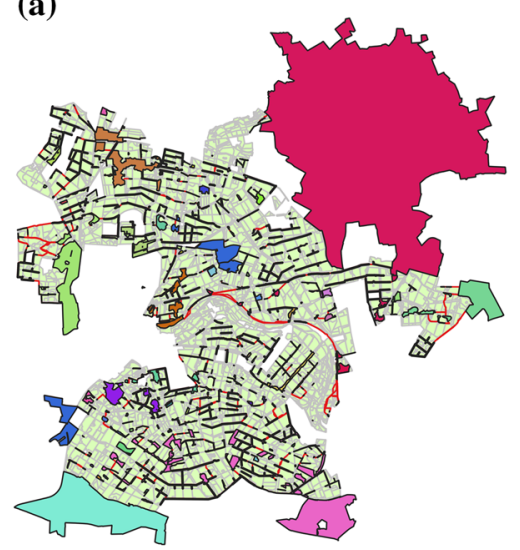

(b)

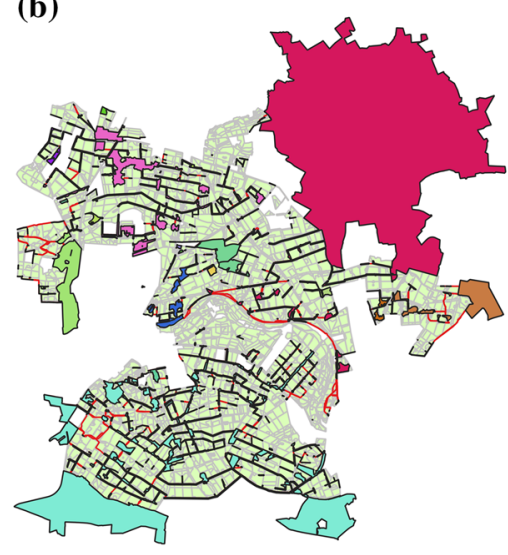

(c)

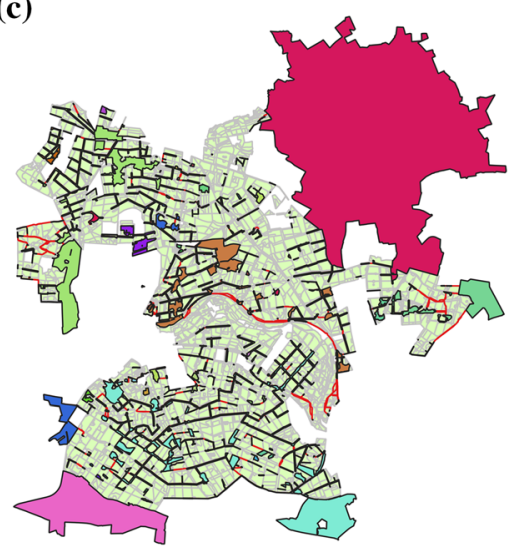

Forest Sub-Components

— Least-Cost Pathways

IIIIIII Individual Network Habitat Patches

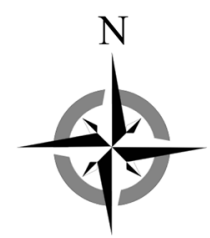

Fig. 7 Results of least-cost path analysis of the flight dispersive guild for management Strategy A (a), Strategy B (b) and the Open Habitat Plan (c). Patches of the same colour within

support the findings of others that continuous corridors can positively improve connectivity for a range of taxa (Sutcliffe and Thomas 1996; Haddad et al. 2003).

Our analysis also demonstrates the negligible benefits of creating clustered patches of open habitat (Strategy A, Fig. 5) for relatively poorly dispersing species, such as many of the most specialist heathland invertebrates in the region. Even when management works were strategically placed in areas with no previous open space, landscape connectivity remained limited over the more contiguous corridor option (Strategy B). Although network size increased with Strategy A, the networks continue to be significantly isolated in the landscape. This highlights the importance of considering the composition of connective habitat when undertaking conservation management or assessments (Perez-Hernandez et al. 2015), especially where inter patch distances are long relative to the dispersal capacity of the individual (Haddad 2000). the landscape are part of the same network with connecting least-cost pathways highlighted

The design of the Open Habitat Plan incorporates features from both hypothetical management strategies tested, resulting in a combination of contiguous and clustered corridors (Fig. 3c). This combined approach is reflected within the calculated landscape metrics for the Open Habitat Plan, which significantly improved connectivity over the Original Forest Condition and the clustered Strategy A, but did not perform as effectively as Strategy B (Fig. 5). It is important to note that the Open Habitat Plan is designed to improve the landscape for many taxa and not just the invertebrate guilds used in this study. Therefore, the creation of open space in the form of widened clusters of trackways may be more important for the persistence of regionally important species with greater dispersal capabilities that require larger home ranges, such as the stone curlew, Burhinus oedicnemus (Green et al. 2000). Although the Open Habitat Plan is restricted by various landscape features (e.g., utility services and archaeological features) it is likely the implementation of this design will have a positive 
influence on the population persistence of heathland invertebrates within the forested landscape. Strategy B provides supportive evidence that the inclusion of contiguous corridors in the Open Habitat Plan will deliver significantly greater connectivity compared to the Original Forest Condition. The inclusion of a mixed strategy of contiguous and clustered elements within the landscape corresponds to conclusions found for other habitat types (Gillies and St Clair 2010; Perez-Hernandez et al. 2015). However, it should be noted that continued maintenance of open habitat will be vital for supporting species associated with early successional habitat (Pedley et al. 2013b; Brunbjerg et al. 2015).

While the LCP analysis provided a useful tool to assess management strategies in the case study, some limitations are evident. For example, by identifying the most optimum route we assume empirical knowledge of the landscape within each individual, therefore our analysis can only represent potential connectivity within the forest (Driezen et al. 2007). With short-life cycles and random walk movements typical of many invertebrate species (Baars 1979), directed movement predicted by our analysis may be rare and only performed by a limited number of individuals by chance. Our analysis is also limited by the lack of detailed dispersal data for the majority of invertebrate species and taxa; even in the extensively studied European heathland landscapes, the best available data only allowed us to derive maximum lifetime dispersal distances for a relatively small number of heathland associated species. Additionally, movements recorded in field studies are typically day-to-day movements that may differ from actual dispersal movements. Dispersal capabilities may also be affected by the life-stage of the species recorded (Paradis et al. 1998; Bonte et al. 2007). By using maximum lifetime dispersal distances, we can at least derive that a species has the ability to disperse this distance in a lifetime but this also limits the reality of our analysis. There is also a large variance in maximum lifetime dispersal distances, both within and between invertebrate families (Online Resource 5), which increases the difficulty of developing an accurate threshold for each guild. Model accuracy would have likely been improved had it focused on dispersal data for a single well studied species (Brost and Beier 2012), but this would be far less effective for use in a conservation management application (Beier et al. 2008). Even if more accurate dispersal distances could be determined, it is unlikely this would result in an alternative conclusion due to the restricted connectivity found in our analysis and the disproportionately large presence of high-cost routes within the forest (Online Resource 6).

\section{Applying the Path-Cost Index}

The Path-Cost Index presented in this study has been developed as a tool to be universal for a wide range of applications within cost-based connectivity modelling. By specifically allowing the formula to be adapted with explicit landscape and species parameters, the model built using the $P C I$ will provide a measure of the functional connectivity of the landscape (With 2002), improving the accuracy of modelling by considering both landscape and behavioural influences of species dispersal (Adriaensen et al. 2003). This adaptability of the index to species specific responses allows it to be tailored toward the individual focus of any connectivity analysis, whether it be single or multiple species approaches, or at a broader scale in classifying habitat vegetation. Moreover, with the current availability of landscape data (via remote sensing or inventories of habitat features such as hedgerow), the $P C I$ reduces the need for empirical field studies and allows an inexpensive, rapid solution for connectivity analysis and conservation planning.

In the presented case study, we demonstrate the PCI's application in connectivity modelling for open habitat specialists within a forestry mosaic landscape, but the formula can be applied in a wide variety of ecological scenarios. This includes connectivity analysis of forestry specialist species, for which an inverse function of the index could be used to apply increasing dispersal resistance as trackways become unshaded. The index could additionally be used to apply variable edge buffers in determining core habitat areas on a finer scale, giving more accurate estimations of habitat loss due to fragmentation (Laurance and Yensen 1991). Furthermore, it is not limited to forest landscapes, any habitat that would be influenced by shade could be incorporated using the $P C I$, such as the influence of riparian vegetation on thermal conditions in aquatic habitats (Broadmeadow et al. 2011) or the habitat suitability of ponds for amphibians (Van Buskirk 2005). Shade 
has significant influence on the microclimate in these aquatic habitats and therefore is important in moderating and reducing temperatures that would otherwise exceed species threshold in changing climates (Broadmeadow et al. 2011). In these scenarios the index could be used to categorise microclimatic conditions for climate change mitigation (MantykaPringle et al. 2014; Greenwood et al. 2016) rather than for dispersal and patch connectivity.

It should be noted that as with any modelling exercise the PCI relies on some simplifying assumptions, such as a constant tree density within individual habitat patches (for plantation forest under clear-fell management this is a reasonable assumption), consistent sunlight hours and, in the case of Thetford Forest invertebrates, that suitable vegetation will colonise areas with suitable habitat conditions. Despite this, robust connectivity models only rely on suitably ranked cost values within the landscape, rather than biologically complex values (Beier et al. 2009). Therefore, if suitable parameters are used to calculate the $P C I$ it has the potential to produce viable costs for connectivity analysis. However, it should be stressed that any management plan instigated after such modelling approaches must implement a programme of monitoring for target species presence, persistence, and movement to provide evidence that can be use in future conservation works (Sutherland et al. 2004).

\section{Conclusion}

The effectiveness of habitat creation and restoration schemes within landscape mosaics will be strongly limited by the ability of target species to disperse between patches. The case study presented here highlights that although forest trackways have the potential to act as dispersal routes for open habitat species, their suitability is limited by multiple microclimatic factors, which result in the isolation of many individual networks. The PCI developed in this study provides an efficient tool to allow rapid cost application of trackways for GIS-weighted resistance models, helping to reduce the time and resources associated with assessing landscape connectivity. The $P C I$ has potential to be parametrised for other linear features and can be used with individual species or guild specific dispersal parameters. Additionally, for the current study the $P C I$ delivered easily definable resistance costs to allow comparative analyses of landscape enhancements plans, providing vital evidence for habitat managers to assess schemes before implementation in the field.

Acknowledgements We thank Neal Armour-Chelu and Richard Brooke from the Forest Commission for helpful comments and site information that contributed to this manuscript and also Dr. H. Mossman and Prof. P. Dolman for early comments on this work.

Open Access This article is licensed under a Creative Commons Attribution 4.0 International License, which permits use, sharing, adaptation, distribution and reproduction in any medium or format, as long as you give appropriate credit to the original author(s) and the source, provide a link to the Creative Commons licence, and indicate if changes were made. The images or other third party material in this article are included in the article's Creative Commons licence, unless indicated otherwise in a credit line to the material. If material is not included in the article's Creative Commons licence and your intended use is not permitted by statutory regulation or exceeds the permitted use, you will need to obtain permission directly from the copyright holder. To view a copy of this licence, visit http://creativecommons.org/licenses/by/4.0/.

\section{References}

Adriaensen F, Chardon JP, De Blust G, Swinnen E, Villalba S, Gulinck H, Matthysen E (2003) The application of 'leastcost' modelling as a functional landscape model. Landsc Urban Plan 64(4):233-247

Armour-Chelu N, Riley R, Brooke R (2014) Open Habitat Implementation Plan for The Forestry Commission Thetford Public Forest Estate 2014 Onward. Forestry Commission, England, UK, pp 1-95

Baars MA (1979) Patterns of movement of radioactive carabid beetles. Oecologia 44(1):125-140

Beier P, Majka DR, Spencer WD (2008) Forks in the road: choices in procedures for designing wildland linkages. Conserv Biol 22(4):836-851

Beier P, Majka DR, Newell SL (2009) Uncertainty analysis of least-cost modeling for designing wildlife linkages. Ecol Appl 19(8):2067-2077

Bertoncelj I, Dolman PM (2013a) Conservation potential for heathland Carabid beetle fauna of linear trackways within a plantation forest. Insect Conserv Divers 6(3):300-308

Bertoncelj I, Dolman PM (2013b) The matrix affects trackway corridor suitability for an arenicolous specialist beetle. J Insect Conserv 17(3):503-510

Bonte D, Van Belle S, Maelfait JP (2007) Maternal care and reproductive state-dependent mobility determine natal dispersal in a wolf spider. Anim Behav 74:63-69

Broadmeadow SB, Jones JG, Langford TEL, Shaw PJ, Nisbet TR (2011) The influence of riparian shade on lowland stream water temperatures in southern England and their viability for brown trout. River Res Appl 27(2):12

Brodie JF, Giordano AJ, Dickson BG, Hebblewhite M, Bernard H, Mohd-Azlan J, Anderson J, Ambu L (2015). Evaluating 
multispecies landscape connectivity in a threatened tropical mammal community. Conserv Biol 29(1):122-132

Brost BM, Beier P (2012) Comparing linkage designs based on land facets to linkage designs based on focal species. PLoS One 7(11):1-13

Brunbjerg AK, Jorgensen GP, Nielsen KM, Pedersen ML, Svenning JC, Ejrnaes R (2015) Disturbance in dry coastal dunes in Denmark promotes diversity of plants and arthropods. Biol Conserv 182:243-253

Bunn AG, Urban DL, Keitt TH (2000) Landscape connectivity: a conservation application of graph theory. J Environ Manag 59(4):265-278

Carter CI, Anderson MA (1987) Enhancement of lowland forest ridesides and roadsides to benefit wild plants and butterflies. Forestry Commission, Research Division

Dolman PM, Sutherland WJ (1992) The ecological changes of Breckland grass heaths and the consequences of management. J Appl Ecol 29(2):402-413

Dolman PM, Panter CJ, Mossman HL (2012) The biodiversity audit approach challenges regional priorities and identifies a mismatch in conservation. J Appl Ecol 49(5):986-997

Dondina O, Kataoka L, Orioli V, Bani L (2016) How to manage hedgerows as effective ecological corridors for mammals: a two-species approach. Agric Ecosyst Environ 231:283-290

Driezen K, Adriaensen F, Rondinini C, Doncaster CP, Matthysen E (2007) Evaluating least-cost model predictions with empirical dispersal data: a case-study using radiotracking data of hedgehogs (Erinaceus europaeus). Ecol Model 209(2-4):314-322

English Nature (2004) Breckland Forest SSSI Site Management Statement. Natural England, Bury St. Edmunds, UK, pp $1-4$

Eycott AE, Watkinson AR, Dolman PM (2006) Ecological patterns of plant diversity in a plantation forest managed by clearfelling. J Appl Ecol 43(6):1160-1171

Fahrig L (2003) Effects of habitat fragmentation on biodiversity. Annu Rev Ecol Evol Syst 34:487-515

Farrell L (1993) Lowland heathland: the extent of habitat change. English Nature, Peterborough

FlowMap Group@SESS-PKU (2020) Least-Cost Path, V0.3 QGIS Plugin. https://github.com/Gooong/LeastCostPath

Forestry Commission (2017a) National Forest Estate Subcompartments England. Forestry Commission England, UK. https://www.forestry.gov.uk/forestry/infd-8g5bya. Accessed 4 Aug 2017

Forestry Commission (2017b) UK Forestry Standard: the Government's approach to sustainable forestry, 4th edn. Forestry Commission, Edinburgh, UK

Gillies CS, St Clair CC (2010) Functional responses in habitat selection by tropical birds moving through fragmented forest. J Appl Ecol 47(1):182-190

Gimingham CH (1992) The lowland heathland management handbook. English Nature, Peterborough

Givnish TJ, Wong SC, Stuart-Williams H, Holloway-Phillips M, Farquhar GD (2014) Determinants of maximum tree height in Eucalyptus species along a rainfall gradient in Victoria. Aust Ecol 95(11):2991-3007

Google Earth (2017) Thetford Forest, UK (February 2007), v7.3.0.3832 edn. Infoterra Ltd \& Blue Sky, pp. http:// www.earth.google.com
Greatorex-Davies JN, Sparks TH, Hall ML (1994) The response of heteroptera and coleoptera species to shade and aspect in rides of coniferised lowland woods in Southern England. Biol Conserv 67(3):255-273

Green RE, Tyler GA, Bowden CGR (2000) Habitat selection, ranging behaviour and diet of the stone curlew (Burhinus oedicnemus) in southern England. J Zool 250:161-183

Greenwood O, Mossman HL, Suggitt AJ, Curtis RJ, Maclean IMD (2016) Using in situ management to conserve biodiversity under climate change. J Appl Ecol 53(3):885-894

Gustafson EJ, Parker GR (1992) Relationships between landcover proportion and indexes of landscape spatial pattern. Landsc Ecol 7(2):101-110

Haddad N (2000) Corridor length and patch colonization by a butterfly, Junonia coenia. Conserv Biol 14(3):738-745

Haddad NM, Bowne DR, Cunningham A, Danielson BJ, Levey DJ, Sargent S, Spira T (2003). Corridor use by diverse taxa. Ecology 84(3):609-615

Haddad NM, Brudvig LA, Clobert J, Davies KF, Gonzalez A, Holt RD, Lovejoy TE, Sexton JO, Austin MP, Collins CD, Cook WM, Damschen EI, Ewers RM, Foster BL, Jenkins CN, King AJ, Laurance WF, Levey DJ, Margules CR, Melbourne BA, Nicholls AO, Orrock JL, Song DX, Townshend JR (2015) Habitat fragmentation and its lasting impact on Earth's ecosystems. Sci Adv 1(2):9

Hemami MR, Watkinson AR, Dolman PM (2005) Population densities and habitat associations of introduced muntjac Muntiacus reevesi and native roe deer Capreolus capreolus in a lowland pine forest. For Ecol Manag 215(1-3):224-238

Hoekstra JM, Boucher TM, Ricketts TH, Roberts C (2005) Confronting a biome crisis: global disparities of habitat loss and protection. Ecol Lett 8(1):23-29

Hothorn T, Bretz F, Westfall P (2008) Simultaneous inference in general parametric models. Biom J 50:346-363

Isaac NJB, Brotherton PNM, Bullock JM, Gregory RD, Boehning-Gaese K, Connor B, Crick HQP, Freckleton RP, Gill JA, Hails RS, Hartikainen M, Hester AJ, Milner-Gulland EJ, Oliver TH, Pearson RG, Sutherland WJ, Thomas CD, Travis JMJ, Turnbull LA, Willis K, Woodward G, Mace GM (2018) Defining and delivering resilient ecological networks: nature conservation in England. J Appl Ecol 55(6):2537-2543

Laurance WF, Yensen E (1991) Predicting the impacts of edge effects in fragmented habitats. Biol Conserv 55(1):77-92

Lawton JH, Brotherton PNM, Brown VK, Elphick C, Fitter AH, Forshaw J, Haddow RW, Hilborne S, Leafe RN, Mace GM, Southgate MP, Sutherland WJ, Tew TE, Varley J, Wynne GR (2010) Making space for nature: a review of England's wildlife sites and ecological network. Report to DEFRA

Lechner AM, Sprod D, Carter O, Lefroy EC (2017) Characterising landscape connectivity for conservation planning using a dispersal guild approach. Landsc Ecol 32(1):99-113

Lin YC, James R, Dolman PM (2007) Conservation of heathland ground beetles (Coleoptera, Carabidae): the value of lowland coniferous plantations. Biodivers Conserv 16(5):1337-1358 
Maclean IMD, Mosedale JR, Bennie JJ (2018) An r package for modelling meso- and microclimate. Methods Ecol Evol 10(2):280-290

Mantyka-Pringle CS, Martin TG, Rhodes JR (2012) Interactions between climate and habitat loss effects on biodiversity: a systematic review and meta-analysis. Glob Chang Biol 18(4):1239-1252

Mantyka-Pringle CS, Martin TG, Moffatt DB, Linke S, Rhodes JR (2014) Understanding and predicting the combined effects of climate change and land-use change on freshwater macroinvertebrates and fish. J Appl Ecol 51(3):572-581

McGarigal K, Marks B (1995) FRAGSTAT: spatial pattern analysis program for quantifying landscape structure. U.S. Department of Agriculture, Forest Service, Pacific Northwest Research Station, Portland

McGarigal K, Cushman SA, Ene E (2012) FRAGSTATS v4: spatial pattern analysis program for categorical and continuous maps. University of Massachusetts, Amherst

Millennium Ecosystem Assessment (2005) Ecosystems and human well-being: Current state and trends. Island Press, Washington, DC

Paradis E, Baillie SR, Sutherland WJ, Gregory RD (1998) Patterns of natal and breeding dispersal in birds. J Anim Ecol 67(4):518-536

Pedley SM (2012) Effects of experimental disturbance on multi-taxa assemblages and traits: conservation implication in a forest-open landscape mosaic. Doctoral thesis, University of East Anglia, UK

Pedley SM, Bertoncelj I, Dolman PM (2013a) The value of the trackway system within a lowland plantation forest for ground-active spiders. J Insect Conserv 17(1):127-137

Pedley SM, Franco AMA, Pankhurst T, Dolman PM (2013b) Physical disturbance enhances ecological networks for heathland biota: a multiple taxa experiment. Biol Conserv 160:173-182

Perez-Hernandez CG, Vergara PM, Saura S, Hernandez J (2015) Do corridors promote connectivity for bird-dispersed trees? The case of Persea lingue in Chilean fragmented landscapes. Landsc Ecol 30(1):77-90

Piessens K, Hermy M (2006) Does the heathland flora in northwestern Belgium show an extinction debt? Biol Conserv 132(3):382-394

Piessens K, Honnay O, Hermy M (2005) The role of fragment area and isolation in the conservation of heathland species. Biol Conserv 122(1):61-69

QGIS Development Team (2009) QGIS Geographic Information System. Open Source Geospatial Foundation. http:// qgis.osgeo.org

R Development Core Team (2018) R: a language and environment for statistical computing, v3.5.1 edn. R Foundation for Statistical Computing, Vienna, Austria

Rayfield B, Pelletier D, Dumitru M, Cardille JA, Gonzalez A (2016) Multipurpose habitat networks for short-range and long-range connectivity: a new method combining graph and circuit connectivity. Methods Ecol Evol 7(2):222-231

Rowland CS, Balzter H, Dawson TP, Luckman A, Patenaude G, Skinner L (2008) Airborne SAR monitoring of tree growth in a coniferous plantation. Int $\mathrm{J}$ Remote Sens 29(13):3873-3889

Ryan MG, Yoder BJ (1997) Hydraulic limits to tree height and tree growth. Bioscience 47(4):235-242

Sparks TH, Greatorex-Davies JN, Mountford JO, Hall ML, Marrs RH (1996) The effects of shade on the plant communities of rides in plantation woodland and implications for butterfly conservation. For Ecol Manag 80:197-207

Sutcliffe OL, Thomas CD (1996) Open corridors appear to facilitate dispersal by ringlet butterflies (Aphantopus hyperantus) between woodland clearings. Conserv Biol 10(5):1359-1365

Sutherland WJ, Pullin AS, Dolman PM, Knight TM (2004) The need for evidence-based conservation. Trends Ecol Evol 19(6):305-308

Taylor PD, Fahrig L, Henein K, Merriam G (1993) Connectivity is a vital element of landscape structure. Oikos 68(3):571-573

Telfer MG, Eversham BC (1996) Ecology and conservation of heathland Carabidae in eastern England. Ann Zool Fenn 33(1):133-138

UKWAS (2012) United Kingdom Woodland Assurance Standard, 3rd edn. United Kingdom Woodland Assurance Standard Steering Group, Edinburgh

Urban DL, Minor ES, Treml EA, Schick RS (2009) Graph models of habitat mosaics. Ecol Lett 12(3):260-273

Van Buskirk J (2005) Local and landscape influence on amphibian occurrence and abundance. Ecology 86(7):1936-1947

Warren MS (1985) The influence of shade on butterfly numbers in woodland rides, with special reference to the wood white Leptidea-sinapis. Biol Conserv 33(2):147-164

Wehling S, Diekmann M (2009) Importance of hedgerows as habitat corridors for forest plants in agricultural landscapes. Biol Conserv 142(11):2522-2530

Wilson MC, Chen XY, Corlett RT et al (2016) Habitat fragmentation and biodiversity conservation: key findings and future challenges. Landsc Ecol 31(2):219-227

With KA (2002) Using percolation theory to assess landscape connectivity and effects of habitat fragmentation. In: Gutzwiller KJ (ed) Applying landscape ecology in biological conservation. Springer New York, New York, pp 105-130

Publisher's Note Springer Nature remains neutral with regard to jurisdictional claims in published maps and institutional affiliations. 